\title{
Observations of lion roars in the magnetosheath by the STAFF/DWP experiment on the Double Star TC-1 spacecraft
}

\author{
K. H. Yearby ${ }^{1}$, H. S. C. K. Alleyne ${ }^{1}$, N. Cornilleau-Wehrlin ${ }^{2}$, O. Santolik ${ }^{3,4}$, M. A. Balikhin ${ }^{1}$, S. N. Walker ${ }^{1}$, \\ A. Fazakerley ${ }^{5}$, and A. Lahiff ${ }^{5}$ \\ ${ }^{1}$ ACSE, University of Sheffield, Mappin Street, Sheffield, S1 3JD, UK \\ ${ }^{2}$ CETP/IPSL, 10-12 Av. de l'Europe, 78140 Vélizy, France \\ ${ }^{3}$ Faculty of Mathematics and Physics, Charles University, V Holesovickach 2, 18000 Praha 8, Czech Republic \\ ${ }^{4}$ Institute of Atmospheric Physics, Bocni II/1401, 14131 Praha 4, Czech Republic \\ ${ }^{5}$ Mullard Space Science Laboratory, Holmbury St. Mary, Dorking, Surrey, RH5 6NT, UK
}

Received: 14 February 2005 - Revised: 12 May 2005 - Accepted: 23 May 2005 - Published: 8 November 2005

Part of Special Issue "Double Star - First Results"

\begin{abstract}
Lion roars are intense, short duration packets of whistler mode waves, observed in the magnetosheath. They are typically seen coincident with the magnetic field minima of mirror mode waves. The orbit of the Double Star TC1 spacecraft $(570 \mathrm{~km}$ by $78970 \mathrm{~km}$, inclination at $28.5 \mathrm{de}-$ grees) is ideal for observations of lion roars as the spacecraft is in the magnetosheath more than $50 \%$ of the time when the apogee is on the dayside. The STAFF/DWP experiment provides the spectral matrix of the three magnetic components at 27 frequencies in the range $10 \mathrm{~Hz}$ to $4 \mathrm{kHz}$, with one second time resolution, and also the waveform up to $180 \mathrm{~Hz}$ at a low duty cycle. The characteristics of lion roars observed are reported. The maximum lion roar intensities appear higher than reported by most previous studies. The electron temperature anisotropy is estimated from the lion roar frequency ratios, and is in reasonably good agreement with plasma measurements. This indicates the presence of a trapped electron component in the mirror mode.
\end{abstract}

Keywords. Magnetospheric physics (Magnetosheath) Space plasma physics (Waves and instabilities; Instruments and techniques)

\section{Introduction}

The Double Star TC-1 spacecraft was launched at 19:06 UTC, 29 December 2003, into an elliptical orbit of $570 \mathrm{~km}$ by $78970 \mathrm{~km}$, inclined at 28.5 degrees. The STAFF/DWP experiment comprises a three axis search coil magnetometer, waveform unit and onboard spectrum analyser. The experiment provides the spectral matrix of the three magnetic components at 27 frequencies in the range $10 \mathrm{~Hz}$ to
$4 \mathrm{kHz}$ with one second time resolution, as well as the waveform up to $180 \mathrm{~Hz}$ at a low duty cycle of $1 \mathrm{~s}$ every $30 \mathrm{~s}$. For a full description of the experiment see Cornilleau-Wehrlin et al. (2005). Unfortunately, the boom holding the experiment antenna failed to deploy, which means interference from the spacecraft systems is very high. Even so, the intense signals known as lion roars are frequently seen in the magnetosheath.

Lion roars are intense, short duration packets of whistler mode waves, typically seen coincident with the magnetic field minima of mirror mode waves. They were first observed by Smith and Tsurutani (1976) using the search coil magnetometer on OGO-5. They found typical frequencies of $120 \mathrm{~Hz}$ and duration normally less than two seconds. Tsurutani et al. (1982) studied lion roars in ISEE data and established that they are related to mirror mode structures and caused by cyclotron instability of anisotropic thermal electrons. More recently, Zhang et al. (1998) reported lion roars observed by the Geotail magnetometer. They reported frequencies in the range $20 \mathrm{~Hz}$ to $300 \mathrm{~Hz}(0.02$ to 0.75 of the electron gyro frequency) and amplitudes typically $0.1 \mathrm{nT}$. Baumjohann et al. (1999) observed lion roars using the Equator-S fluxgate magnetometer. They report typical amplitudes of 0.5 to $1 \mathrm{nT}$ at frequencies around one tenth of the electron gyro frequency. The average duration of individual wave packets was 250 milliseconds. However the sampling rate of their instrument limits the study to waves less than $64 \mathrm{~Hz}$.

Maksimovic et al. (2001) studied the polarisation and propagation of lion roars using two short periods of data from the STAFF spectrum analyser on the four Cluster spacecraft. They report a $\log$ normal distribution of intensities with an average power spectral density of $10^{-4} \mathrm{nT}^{2} \mathrm{~Hz}^{-1}$ at a frequency of 0.2 of the electron gyro frequency. 
Table 1. Average lion roar intensity, wave frequency, and proportion occurring at magnetic field minimum.

\begin{tabular}{lll}
\hline Quantity & Average & \\
\hline Power spectral density & $9.57 \times 10^{-4} \mathrm{nT}^{2} \mathrm{~Hz}^{-1}$ & \\
Integrated power & $0.0454 \mathrm{nT}^{2}$ & $f / f_{c e}=0.17$ \\
Frequency $(f)$ & $115 \mathrm{~Hz}$ & \\
Proportion occurring at magnetic field minimum & $46 \%$ & \\
\hline
\end{tabular}

(a)

\section{Double Star $15 / 03 / 2004$ to $17 / 04 / 2004$}

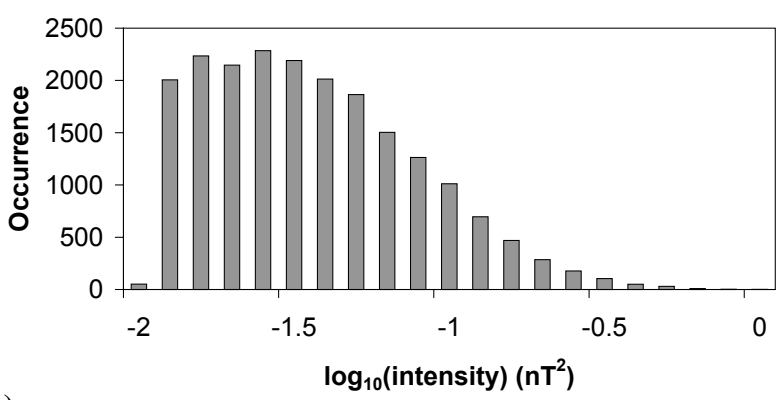

(b)

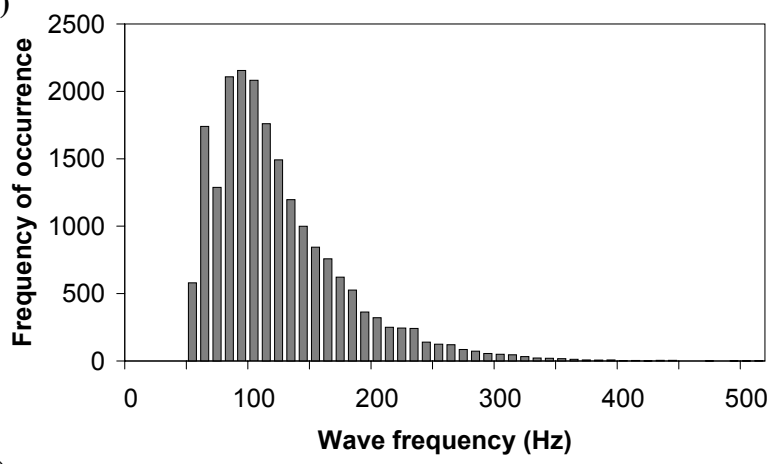

(c)

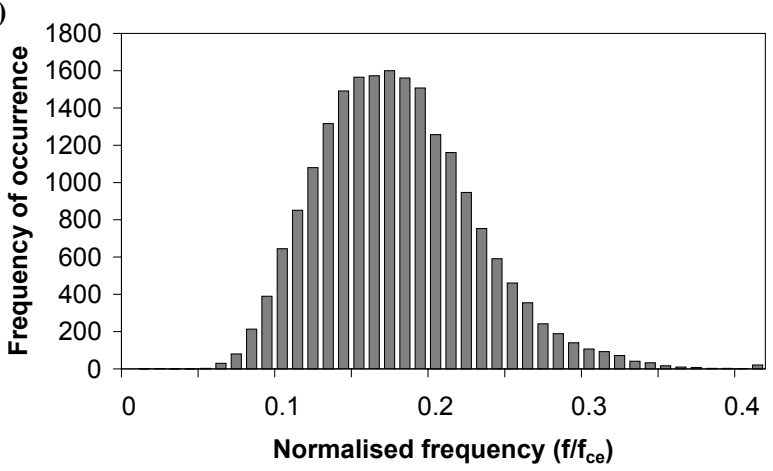

Fig. 1. Histograms of the logarithm of the lion roar intensity (a), average frequency (b), and normalised frequency $f / f_{c e}$ (c).

\section{Data and analysis}

Approximately one month of data from 15 March to 17 April 2004 has been analysed by a semi-automated procedure to determine the characteristics of lion roars observed in that period. During this time the spacecraft entered the morning to noon side magnetosheath (08:00 to 12:00 MLT) and frequently reached the bowshock.
The data were processed as follows. First, summary spectrograms were scanned visually to determine periods when lion roars may be present, and where no other intense wave activity was present. Particle data was also checked to make sure the spacecraft was in the magnetosheath. The data during this period was processed using the noise reduction algorithm described in Cornilleau-Wehrlin et al. (2005), and averaged into 4-s blocks. After noise reduction, the average power spectral density of the background spectrum (with no natural signals present) varied from $10^{-5} \mathrm{nT}^{2} \mathrm{~Hz}^{-1}$ at $40 \mathrm{~Hz}$ to $10^{-8} \mathrm{nT}^{2} \mathrm{~Hz}^{-1}$ at $380 \mathrm{~Hz}$. This is much less than the reported lion roar intensities, so we conclude that the lion roar measurements are not significantly effected by the spacecraft noise.

Each spectrum was then scanned to find the bin containing the highest power spectral density, and the five bins centred on this maximum used to compute the integrated power and average frequency. The bandwidth of the integrated power measurement was at least $100 \mathrm{~Hz}$ and sufficient to contain the complete lion roar spectrum. If the integrated power was greater than $0.01 \mathrm{nT}^{2}$ and the frequency greater than $50 \mathrm{~Hz}$ this was taken to be a lion roar (the $50 \mathrm{~Hz}$ limit was applied because of the higher level of interference below this frequency). These comprised approximately 20000 spectra, that is about $5 \%$ of all spectra acquired outside the magnetopause during this period.

DC magnetic field data was provided by the Flux Gate Magnetometer (Carr et al., 2005). The magnetic field data at the time of each lion roar event was examined to determine the magnitude of the field at the time of the event. This was compared to that immediately before and after to determine if the event occurred at a local minimum in the field magnitude.

A summary of the results are shown in Fig. 1 and Table 1. The lion roar intensities are somewhat higher than those reported previously by most authors, although comparison is not straight forward because of the different units used. Most previous authors report peak amplitudes in nT which is appropriate for waveform measurements, but spectral measurements give the power spectral density and integrated power. The latter may be compared to amplitudes by noting that the integrated power in the frequency domain is equal to the mean power in the time domain (Parseval's theorem), and that the root mean square (RMS) amplitude is simply the square root of the mean power. For a series of wave packets the peak amplitude is approximately twice the RMS amplitude. 
Double Star $15 / 03 / 2004$ to $17 / 04 / 2004$

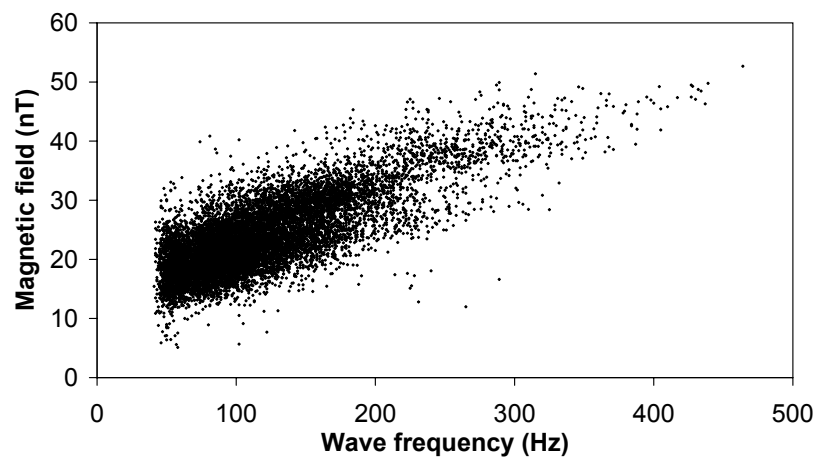

Fig. 2. Scatter plot of DC magnetic field magnitude versus lion roar frequency.

Smith and Tsurutani (1976) report amplitudes in the range 0.04 to $0.16 \mathrm{nT}$, with an average of $0.085 \mathrm{nT}$, while Zhang et al. (1998) report an average amplitude of $0.11 \mathrm{nT}$. Maksimovic et al. (2001) report an average power spectral density of $10^{-4} \mathrm{nT}^{2} \mathrm{~Hz}^{-1}$. In our dataset the average power spectral density is $9.57 \times 10^{-4} \mathrm{nT}^{2} \mathrm{~Hz}^{-1}$, and the average integrated power $0.045 \mathrm{nT}^{2}$. The corresponding peak amplitude, averaged over all events is $0.4 \mathrm{nT}$. In a few cases the integrated power exceeds $0.3 \mathrm{nT}^{2}$. These are seen at frequencies up to $300 \mathrm{~Hz}$. Baumjohann et al. (1999) report lion roars of this amplitude, but their study was limited to frequencies less than $50 \mathrm{~Hz}$.

The average wave frequency of $115 \mathrm{~Hz}$ is quite typical of that reported previously, although the ratio $f / f_{c e}$ of 0.17 is somewhat higher than reported recently (Zhang et al., 1998; Baumjohann et al., 1999). The explanation may lie in the range of frequencies observed. Figure 2 is a scatter plot of the magnetic field magnitude at the time of the lion roar, versus the wave frequency. It is clear that at lower frequencies the magnetic field is not reduced in the same proportion, so the ratio $f / f_{c e}$ tends to be lower. If we compute the average $f / f_{c e}$ using only lion roars with frequencies less than $70 \mathrm{~Hz}$, the value is 0.11 , similar to that reported by the other authors.

Around $46 \%$ of events were associated with magnetic field minima, a little higher than the $30 \%$ reported by Zhang et al. (1998). The observation of lion roars not associated with magnetic field minima may imply that they are observed remotely from their source, or that lion roars are generated on the flanks of the mirror modes as well as at the minima.

In Fig. 3 we show the waveform of a lion roar recorded by the waveform capture mode of the STAFF experiment. The general appearance is that of a large number of overlapping wave packets. The measured peak amplitude (resultant of $B_{x}$ and $B_{y}$ ) is $1.25 \mathrm{nT}$, whilst the mean power over the duration of the record is $0.3 \mathrm{nT}^{2}$. In the frequency domain the maximum power spectral density is $0.012 \mathrm{nT}^{2} \mathrm{~Hz}^{-1}$ at $70 \mathrm{~Hz}$. The average packet duration is $70 \mathrm{~ms}$ and the average number of cycles per packet is 5 . These characteristics are similar to those reported by Baumjohann et al. (1999) with the exception of the higher frequency and corresponding compressed time scale.

\section{Double Star STAFF/MWF 16/03/2004}

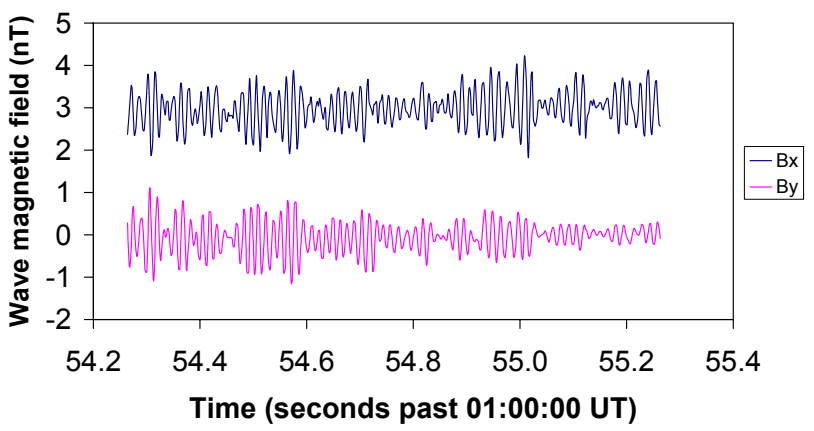

Fig. 3. Lion roar waveform measured by the $\mathrm{X}$ and $\mathrm{Y}$ antenna axes. The $\mathrm{X}$ trace has been offset by $3 \mathrm{nT}$ for clarity. The sensor does not measure the DC component of the field.

Table 2. Double Star and Cluster spacecraft position at 16 March 2004, 00:20 UTC.

\begin{tabular}{lccc}
\hline Spacecraft & X gse $(\mathrm{km})$ & Y gse $(\mathrm{km})$ & Z gse $(\mathrm{km})$ \\
\hline Double Star TC-1 & 76315 & -24721 & -11189 \\
Cluster SC1 & 84051 & -4167 & 30086 \\
\hline
\end{tabular}

Spectrograms of lion roars observed during the same period on both Double Star and Cluster are shown in Fig. 4. The Cluster data shown is for spacecraft 1, but the data is very similar on the other spacecraft, as their separation is about $200 \mathrm{~km}$ for this period of time. Although lion roars are observed at both locations, there does not appear to be a direct correspondence between the two sets of observations. This is not surprising as the two locations are separated by about $47000 \mathrm{~km}$ which is large compared to the size of the mirror mode structures, the bigger dimension of which being of the order of a few thousand kilometres (see e.g. Lucek et al., 2001). The spacecraft positions are given in Table 2 .

The analysis in Fig. 4 is performed using the methods encoded in the computer program PRASSADCO (Santolik, 2000). The data is first transformed into a coordinate system defined by the DC magnetic field, where the $\mathrm{z}$-axis is parallel to the magnetic field, and the $\mathrm{x}$-axis lies in the plane defined by the magnetic field and the direction to the Sun. The data has not been processed for noise reduction as this causes the loss of direction and polarisation information. Even so, the intense lion roars are clearly visible.

The top panel of each set in Fig. 4 shows the intensity power spectrum whilst the lower panels show the ellipticity, polar angle, azimuthal angle and planarity of polarisation. The polarisation and direction parameters are determined using singular value decomposition (Santolik et al., 2003). These confirm the generally accepted characteristics of lion roars, that is right hand circular polarisation (ellipticity +1 ) with a propagation direction close to the magnetic field direction (polar angle usually less than $20^{\circ}$ ). 


\section{Double Star 1 STAFF Spectral matrix}
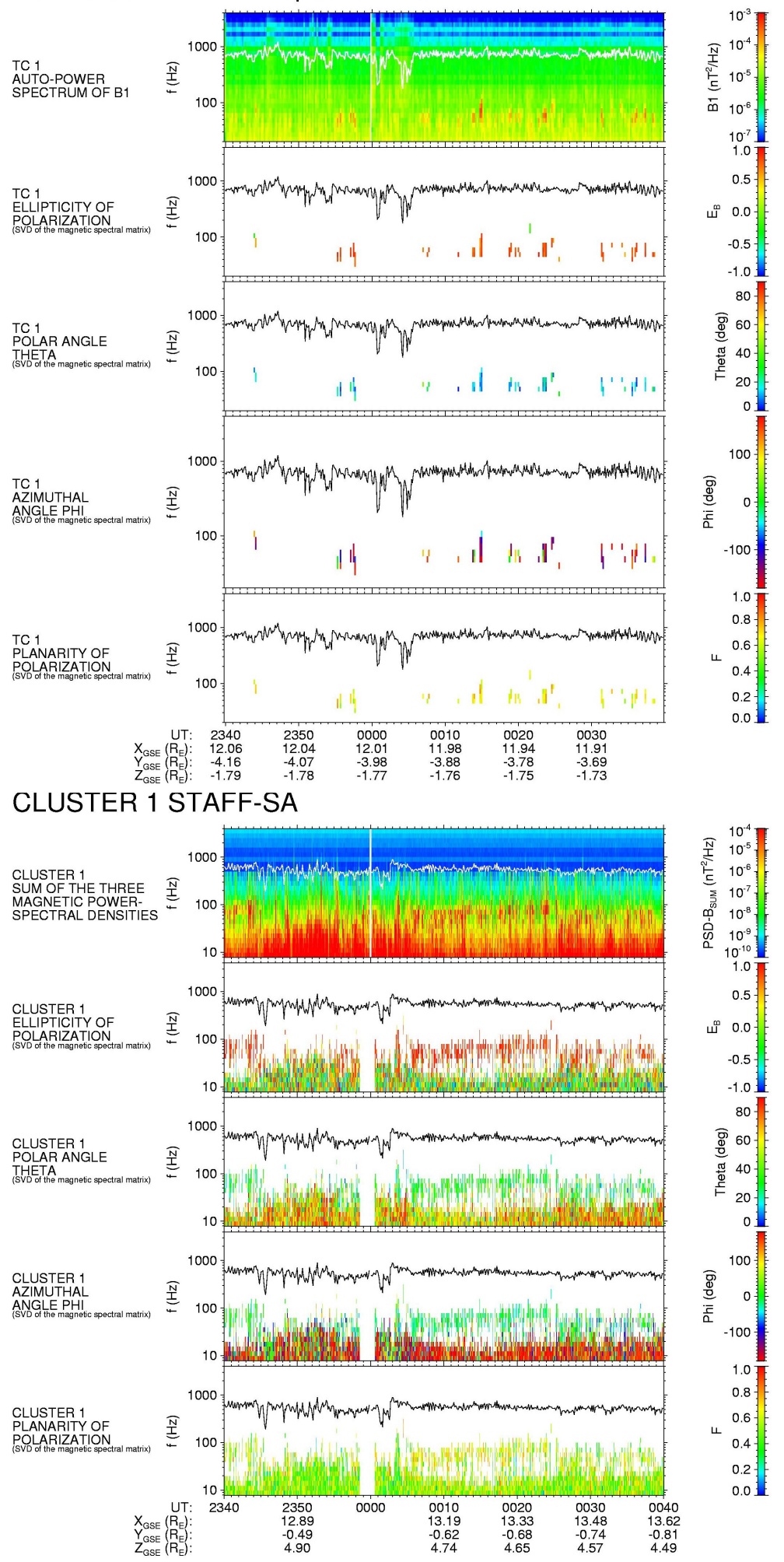

Fig. 4. Spectrograms acquired simultaneously on Double Star and Cluster SC1 for the period 15 March 2004, 23:40 to 16 March 2004, 00:40 UTC. The five panels show the power spectrum, ellipticity, polar angle, azimuthal angle, and planarity of polarisation. The thin lines show the electron gyro frequency. The data is presented in magnetic field aligned coordinates. 


\section{Discussion}

Lion roar frequencies can be used to estimate the temperature anisotropy of the plasma using the linear theory of whistler mode instability. The minimum electron temperature anisotropy $\mathrm{A}_{e}$ needed for the waves at a given frequency $f$ to be amplified (see Kennel and Petschek, 1966) is given by:

$A_{e}>1 /\left(\left(f_{c e} / f\right)-1\right)$

For a bimaxwellian distribution function the anisotropy $A_{e}=\left(T_{\perp}-T_{/ /}\right) / T_{/ /}$.

The observed lion roar waveforms have a fairly constant frequency, and the bandwidth in the frequency domain is due mainly to the short duration of the wave packets. Therefore we consider it reasonable to use the average frequency of each lion roar spectrum in Eq. (1). In Table 3 we compare the temperature anisotropy estimated for six lion roar events, with the maximum temperature anisotropy measured by the PEACE instrument (Fazakerley et al., 2005) near the time of the event. The PEACE instrument measures electron fluxes in the eV-25 keV range, which is quite appropriate for lion roars study for which the resonant energy is estimated to be about $250 \mathrm{eV}$. The data is provided at spin resolution $(4 \mathrm{~s})$, but only alternate spins measure the energies of the magnetosheath plasma. With the exception of one event the agreement is fairly good. The average frequency ratio over all the events in this study is 0.17 , which corresponds to a temperature anisotropy of 0.2 . This is also typical of the maximum temperature anisotropy measured by PEACE in the magnetosheath. This agreement indicates the presence of a trapped electron component in the mirror mode. This was inferred by Baumjohann et al. (1999), but could not be confirmed due to the absence of particle data.

The propagation direction of lion roars is closely aligned with the ambient field. Smith and Tsurutani (1976) reported propagation angles less than 30 degrees, while Zhang et al. (1998) obtained typical angles of 10 degrees. The observations reported here (see Fig. 4) are also consistent with these results. Baumjohann et al. (1999) report an average cone angle of only 0.3 degrees. Their observations were performed on individual wave packets, and they attribute the larger angles seen by previous authors to variations in the magnetic field direction that occur over a lion roar event lasting several seconds. This may be the case, but their observations were restricted to frequencies less than $64 \mathrm{~Hz}$, and it would be useful to repeat their analysis at higher frequencies.

This cannot be done with sufficient accuracy using existing Cluster waveform data because the amplitude range is too limited, whilst Double Star data is of limited accuracy due to the high level of interference. However, we plan to perform this study using new Cluster data acquired using a higher amplitude range. The Cluster tetrahedron with separations presently about $1500 \mathrm{~km}$, in conjunction with Double Star at separations as low as $20000 \mathrm{~km}$ from Cluster should be well suited to multi-scale observations of the waves within mirror mode structures.
Table 3. The electron temperature anisotropy estimated from the frequencies of 6 lion roar events occurring on 16 March 2004, and measured by PEACE near the same time.

\begin{tabular}{ccccc}
\hline Time & $f(\mathrm{~Hz})$ & $f / f_{c e}$ & $A_{e}$ (wave) & $A_{e}$ (PEACE) \\
\hline 00:09:02 & 67 & 0.111 & 0.12 & 0.12 \\
00:07:46 & 116 & 0.180 & 0.22 & 0.18 \\
00:09:42 & 78 & 0.123 & 0.14 & 0.14 \\
00:13:54 & 108 & 0.191 & 0.24 & 0.03 \\
00:14:56 & 135 & 0.223 & 0.29 & 0.20 \\
00:18:54 & 116 & 0.186 & 0.23 & 0.24 \\
\hline
\end{tabular}

The intensity of lion roars has important consequences for the design of wave experiments operating in the magnetosheath. For example, using the standard waveform compression mode, the Cluster STAFF experiment can accurately record waveforms of up to only $0.2 \mathrm{nT}$ amplitude, less than the lion roar mean amplitude of $0.4 \mathrm{nT}$ observed in this study. Future Cluster observations in the magnetosheath will use an alternate mode with a range of $0.8 \mathrm{nT}$, the highest available.

\section{Conclusions}

The characteristics of lion roar events occurring over a one month period are reported. The average frequency ratio is 0.17 . The corresponding temperature anisotropy estimated using linear theory is in reasonably good agreement with plasma measurements, which indicates the presence of a trapped electron component in the mirror mode. Amplitudes of $1 \mathrm{nT}$ or more at frequencies up to $300 \mathrm{~Hz}$ are seen. This is higher than reported at these frequencies by previous work, and this has important implications for the design of wave experiments that are to operate in the magnetosheath. The new characteristics of lion roars have been obtained thanks to the frequency coverage of the STAFF-DWP experiment, broader than on most previous experiments used to study these waves and also to the complementary continuous spectrum analyser coverage and snapshot of waveform data up to $200 \mathrm{~Hz}$.

Acknowledgements. The refurbishment of the Cluster STAFFDWP experiment was funded by ESA. We thank C. Carr and the FGM team for the use of magnetic field data, and H. Reme for HIA ion data. We thank the two referees for helpful comments received following their review of the paper.

Topical Editor T. Pulkkinen thanks M. Maksimovic and R. A. Treumann for their help in evaluating this paper.

\section{References}

Baumjohann, W., Treumann, R. A., Georgescu, E., Haerendel, G., Fornacon, K.-H., and Auster, U.: Waveform and packet structure of lion roars, Ann. Geophys., 17, 1528-1534, 1999,

SRef-ID: 1432-0576/ag/1999-17-1528.

Carr, C., Brown, P., Zhang, T. L., Gloag, J., Horbury, T., Lucek, E., Magnes, W., O’Brien, H., Oddy, T., Auster, U., Austin, P., Ay- 
dogar, O., Balogh, A., Baumjohann, W., Beek, T., Eichelberger, H., Fornacon, K.-H., Georgescu, E., Glassmeier, K.-H., Ludlam, M., Nakamura, R., and Richter, I.: The Double Star magnetic field investigation: instrumentation design, performance and highlights of the first year's observations, Ann. Geophys., 23, 2713-2732, 2005.

Cornilleau-Wehrlin, N., Alleyne, H. S. C., Yearby, K. H., de la Porte de Vaux, B., Santolik, O., Parrot, M., Attié, D., Robert, P., Bouzid, V., and Herment, D.: The STAFF-DWP wave instrument on the DSP equatorial spacecraft: description and first results, Ann. Geophys., 23, 2785-2801, 2005.

Fazakerley, A. N., Carter, P. J., Watson, G., Spencer, A., Sun, Y. Q., Coker, J., Coker, P., Kataria, D. O., Fontaine, D., Liu, Z. X., Gilbert, L., He, L., Lahiff, A. D., Mihaljèiæ, B., Szita, S., Taylor, M. G. G. T., Wilson, R. J., Dedieu, M., and Schwartz, S. J.: The Double Star plasma electron and current experiment, Ann. Geophys., 23, 2733-2756, 2005.

Kennel, C. F. and Petschek, H. E.: Limit on stably trapped particle fluxes, J. Geophys. Res., 77, 1, 1966.

Lucek, E. A., Dunlop, M. W., Horbury, T. S., Balogh, A., Brown, P., Cargill, P., Carr, C., Fornaçon, K.-H., Georgescu, E., and Oddy, T.: Cluster magnetic field observations in the magnetosheath: four point measurements of mirror structures, Ann. Geophys., 19, 1421-1428, 2001,

SRef-ID: 1432-0576/ag/2001-19-1421.
Maksimovic, M., Harvey, C. C., Santolik, O., Lacombe, C., de Conchy, Y., Hubert, D., Pantellini, F., Cornilleau-Wehrlin, N., Dandouras, I., Lucek, E. A., and Balogh, A.: Polarisation and propagation of lion roars in the dusk side magnetosheath, Ann. Geophys., 19, 1429-1438, 2001,

SRef-ID: 1432-0576/ag/2001-19-1429.

Santolik, O.: Propagation Analysis of STAFF-SA Data with Coherency Tests, LPCE/NTS/073.B Lab. Phys. Chimie Environ./CNRS, Orleans, France, 2000.

Santolik, O., Parrot, M., and Lefeuvre, F.: Singular value decomposition methods for wave propagation analysis, Radio Sci. 38, 1010, doi:10.1029/2000RS002523, 2003.

Smith, E. J. and Tsurutani, B. T.: Magnetosheath lion roars, J. Geophys. Res., 81, 2261-2266, 1976.

Tsurutani, B. T., Smith, E. J., Anderson, R. R., Ogilvie, K. W., Scudder, J. D., Baker, D. N., and Bame, S. J.: Lion roars and nonoscillatory drift mirror waves in the magnetosheath, J. Geophys. Res., 87, 6060-6072, 1982.

Zhang, Y., Matsumoto, H., and Kojima, H.: Lion roars in the magnetosheath: The Geotail observations, J. Geophys. Res., 103, 4615-4626, 1998. 